\begin{tabular}{|c|c|c|}
\hline \multirow{2}{*}{$\begin{array}{r}\text { Case Reports in } \\
\text { Gastroenterology }\end{array}$} & \multicolumn{2}{|c|}{ Case Rep Gastroenterol 2018;12:153-157 } \\
\hline & $\begin{array}{l}\text { DOI: 10.1159/000488524 } \\
\text { Published online: April 24, } 2018\end{array}$ & $\begin{array}{l}\text { (c) } 2018 \text { The Author(s) } \\
\text { Published by S. Karger AG, Basel } \\
\text { www.karger.com/crg }\end{array}$ \\
\hline & \multicolumn{2}{|c|}{$\begin{array}{l}\text { This article is licensed under the Creative Commons Attribution-NonCommercial } 4.0 \\
\text { International License (CC BY-NC) (http://www.karger.com/Services/OpenAccessLicense). } \\
\text { Usage and distribution for commercial purposes requires written permission. }\end{array}$} \\
\hline
\end{tabular}

\title{
Ascaris lumbricoides Discharge from the Mouth
}

\author{
Yuya Kobayashi Jun Tsuyuzaki \\ Komoro Kosei General Hospital, Komoro, Japan
}

\section{Keywords}

Ascaris lumbricoides · Mouth · Billroth I resection · Proton pump inhibitor

\begin{abstract}
A 68-year-old Japanese man presented with Ascaris lumbricoides discharge from his mouth. The infection was suspected to have occurred while the patient was in the Philippines. This $A$. lumbricoides migration occurred because a proton pump inhibitor was used and Billroth I resection had been performed, which reduced gastric acid secretion and increased gastric $\mathrm{pH}$. In addition, the pylorus had been removed during Billroth I resection, enabling easy access to the stomach. The number of imported foods, of infected migrants and refugees, and of overseas travels is increasing, and these factors may lead to an increase in A. lumbricoides infection even in countries with a typically low incidence of such infections. Clinicians should bear in mind that parasitic infections may occur in nonendemic areas.

(C) 2018 The Author(s)

Published by S. Karger AG, Basel
\end{abstract}

\section{Introduction}

Ascaris lumbricoides is a common parasite affecting one-quarter of the world's population. This parasite is commonly observed in countries where feces are used as a fertilizer and in the absence of sewer systems, particularly in tropical and subtropical areas [1]. This disease was prevalent in Japan around the time of the Second World War but is now rarely ob-

\section{KARGER}


served. The use of artificial manure without human feces and of sewer systems has reduced the incidence of parasitic infections. A. lumbricoides infection occurs by ingestion of their eggs that contaminate soil or food. The eggs develop in the stomach and pass through the small intestine, liver, and lung and finally settle in the small intestine. The infection is generally asymptomatic; however, serious complications, such as anemia, ileus, eosinophilic pneumonia, cholangitis, and pancreatitis, may develop concomitantly [2]. Here, we report a rare case of A. lumbricoides infection wherein the parasite was discharged through the host's mouth. Although there have been a few reports on this topic, to our knowledge, this is the first report that clearly describes the causes.

\section{Case Presentation}

The patient was a 68-year-old Japanese man. He underwent partial stomach resection via Billroth I 3 years ago for gastric cancer and was taking esomeprazole (20 mg/day). His partner was a Filipino, and he traveled to the Philippines 6 times a year. The patient was based in Manila, the capital of the Philippines, and did not visit the countryside. He reported consuming food from roadside stalls and avoiding raw food. Five days prior to presentation, he complained of an abnormal feeling in his pharynx that improved with repeated swallowing. On the day before presentation, the patient experienced similar symptoms, coughed, felt an obstruction in his mouth, and manually pulled out a 20 -cm-long worm (Fig. 1). On admission, the patient's vital signs were normal, and he had no other complaints. No abnormalities were observed in the blood tests, and no rise in immunoglobulin E (33 IU/dL) or eosinophilia was detected. Chest X-ray and abdominal computed tomography findings were normal. To identify the parasitic agents, a fecal examination was performed; we detected unembryonated eggs and suspected Ascaris spp. infection. Emergency upper gastrointestinal endoscopy was performed. Although no worm was found, a mild esophageal hiatus hernia was observed. The gastric fluid $\mathrm{pH}$ was 6.8. The worm was identified as a female A. lumbricoides. One month after treatment, eggs were no longer present in the patient's stools.

\section{Discussion}

The parasitic form of $A$. lumbricoides is unique. Its life cycle has 4 stages: embryonation, ingestion, larva migration, and maturation. Eggs are excreted in feces and are latent in the soil. The eggs adhere to vegetables, and infection begins on the ingestion of the eggs. The egg membrane is digested by gastric juice, releasing the internal larvae. When the larvae reach the small intestine, they pass through the portal vein, liver, hepatic vein, right heart, and reach the lung. The larvae invade the alveoli, ascend to the pharynx, enter the esophagus, and mature into adult worms in the small intestine. The infection is generally asymptomatic, but complications, such as ileus, eosinophilic pneumonia, cholangitis, and pancreatitis, may develop in some cases [2].

Movement of $A$. lumbricoides to the esophagus is a rare event. Esophageal ascariasis was reported in a 15-year-old boy in India and in a 70-year-old woman in China [3, 4]. In these cases, the X-ray barium images showed the shadow of $A$. lumbricoides in the esophagus. Two more cases have reported the discharge of A. lumbricoides through the host's mouth. However, both the reported patients were unconscious, with one having been involved in a road traffic accident and the other just having undergone a successful cardiopulmonary resuscita- 
tion $[5,6]$. The behavior of $A$. lumbricoides, being discharged through the host's mouth, may

have been caused by a decrease in digestive tract activity.

In the current case, there are 2 reasons for this behavior. A. lumbricoides does not thrive in an acidic environment and typically resides in the ileum as the main parasitic site. The strong motor activity of this worm enables it to remain in the ileum without succumbing to intestinal peristalsis. When it comes into contact with gastric acid while accidentally traveling toward the mouth, it generally changes direction to move toward the anal side. Occasionally, it enters the biliary tract in an attempt to avoid gastric acid and obstructs the bile duct. Hepatobiliary and pancreatic ascariasis frequently occur in developing countries and are the etiological causes in $36.7,23,14.5$, and $12.5 \%$ of all cases of biliary disease, acute pancreatitis, liver abscesses, and biliary lithiasis, respectively, in Kashmir, India [2]. In the current case, the intake of esomeprazole, a proton pump inhibitor, and being subjected to Billroth I resection caused reduction in gastric acid secretion and increased gastric $\mathrm{pH}$ to 6.8; this made it easy for $A$. lumbricoides to migrate past the stomach to the mouth. Esomeprazole increases the $\mathrm{pH}$ to up to approximately 6 and maintains a $\mathrm{pH}$ of 4 or higher during $56.4 \%$ of the day [7]. In addition, gastrectomy through Billroth I resection also increases gastric $\mathrm{pH}$.

The second reason for the migration of the worm past the stomach in this case could be that the pylorus, which is the narrowest part in the digestive tract, was removed during Billroth I resection, thus enabling easy access into the stomach. Billroth I resection is used widely in gastrectomy to reconstruct the pylorus of the stomach. As a consequence, it allows backflow of bile, pancreatic juice, and other intestinal juices, which are likely to stagnate in the residual stomach. Endoscopy also revealed an esophageal hiatus hernia. Billroth I resection increases the risk of reflux esophagitis due to a loose lower esophageal sphincter owing to the operation and hormonal changes $[8,9]$.

The patient was suspected to have acquired the infection in the Philippines. Fertilized eggs have 3 thick layers, rendering antibiotics ineffective. Moreover, A. lumbricoides eggs are known to be more resilient compared to other parasite eggs. The eggs remain infectious for 2 years even at freezing temperatures, indicating that they can survive during winter and in contaminated imported frozen food $[10,11]$. Studies have shown that the rate of contamination by parasitic agents worldwide is high, accounting for $31.2 \%$ of vegetables bought from bazaars in Pakistan [12], 66.3\% of vegetables bought from bazaars in Morocco [13], 34.7\% of vegetables bought from bazaars in Poland [14], and 25\% of vegetables bought from bazaars in Iran [15]. The number of travelers has markedly increased in the past decade, and these travelers are at risk of infection. Due to the development of logistics and diversification of food, the amount of imported food has increased, and even fresh vegetables are available at cheap rates. Japan is highly dependent on imported foods, and care should be taken with regard to food contaminated with parasitic agents. In addition, organically grown vegetables have become increasingly popular, but there is a risk of infection with pesticide-free and organic fertilizers. Furthermore, the number of immigrants and refugees from areas at a high risk of infection is expected to increase. In fact, in the United States, approximately 4 million people are infected and most of these are immigrants [2]. Clinicians must be aware of parasitic infections because diseases may occur in nonendemic areas.

\section{Statement of Ethics}

The authors have no ethical conflicts to disclose. 


\section{Case Reports in \\ Gastroenterology}

Kobayashi and Tsuyuzaki: Ascaris lumbricoides Discharge from the Mouth

\section{Disclosure Statement}

The authors have no conflicts of interest to declare.

\section{References}

1 de Silva NR, Brooker S, Hotez PJ, Montresor A, Engels D, Savioli L. Soil-transmitted helminth infections: updating the global picture. Trends Parasitol. 2003 Dec;19(12):547-51.

2 Khuroo MS. Ascariasis. Gastroenterol Clin North Am. 1996 Sep;25(3):553-77.

3 Zheng PP, Wang BY, Wang F, Ao R, Wang Y. Esophageal space-occupying lesion caused by Ascaris lumbricoides. World J Gastroenterol. 2012 Apr;18(13):1552-4.

4 Gandhi D, Srivastava DN, Batra B, Chandra S. Radiological demonstration of ascaris in esophagus. Indian Pediatr. 1999 Dec;36(12):1270-2.

5 Margery J, Niang A. Adult ascaris worm passing from the mouth. Am J Trop Med Hyg. 2011 Sep;85(3):395.

6 Hajizadeh M, Rahimi MT, Spotin A, Ahmadpour E. A rare cause of dysphagia: pharyngeal ascariasis. J Parasit Dis. 2016 Dec;40(4):1411-3.

7 Warrington S, Baisley K, Boyce M, Tejura B, Morocutti A, Miller N. Effects of rabeprazole, $20 \mathrm{mg}$, or esomeprazole, $20 \mathrm{mg}$, on 24-h intragastric $\mathrm{pH}$ and serum gastrin in healthy subjects. Aliment Pharmacol Ther. 2002 Jul;16(7):1301-7.

8 Yamashita Y, Inoue H, Ohta K, Yoshida K, Miyahara E, Hirai T et al. Manometric and hormonal changes after distal partial gastrectomy. Aliment Pharmacol Ther. 2000 Apr;14 Suppl 1:166-9.

9 Fujiwara Y, Nakagawa K, Kusunoki M, Tanaka T, Yamamura T, Utsunomiya J. Gastroesophageal reflux after distal gastrectomy: possible significance of the angle of His. Am J Gastroenterol. 1998 Jan;93(1):11-5.

10 World Health Organization, Regional Office for the Eastern Mediterranean, Regional Centre for Environmental Health Activities. Integrated guide to: sanitary parasitology. Amman, Jordan: World Health Organization; 2004.

11 Lubis IN, Pasaribu S, Lubis CP. Current status of the efficacy and effectiveness of albendazole and mebendazole for the treatment of Ascaris lumbricoides in North-Western Indonesia. Asian Pac J Trop Med. 2012 Aug;5(8):605-9.

12 Shafa-ul-Haq, Maqbool AZ, Khan UJ, Yasmin G, Sultana R. Parasitic contamination of vegetables eaten raw in Lahore. Pakistan J Zool. 2014;46:1303-9.

13 Hajjami K, Ennaji MM, Amdiouni H, Fouad S, Cohen N. Parasitic contamination on fresh vegetable consumed in Casablanca city (Morocco) and risk for consumer. Int J Sci Technol. 2013;2:543-9.

14 Kłapeć T, Borecka A. Contamination of vegetables, fruits and soil with geohelmints eggs on organic farms in Poland. Ann Agric Environ Med. 2012;19(3):421-5.

15 Daryani A, Ettehad GH, Sharif M, Ghorbani L, Ziaei H. Prevalence of intestinal parasites in vegetables consumed in Ardabil, Iran. Food Control. 2008;19(8):790-4. 


\begin{tabular}{ll|l} 
Case Reports in & \begin{tabular}{l} 
Case Rep Gastroenterol 2018;12:153-157 \\
\cline { 2 - 3 } Gastroenterology
\end{tabular} & $\begin{array}{l}\text { ○ 2018 The Author(s). Published by S. Karger AG, Basel } \\
\text { www.karger.com/crg }\end{array}$ \\
\cline { 2 - 3 } & Kobayashi and Tsuyuzaki: Ascaris lumbricoides Discharge from the Mouth
\end{tabular}

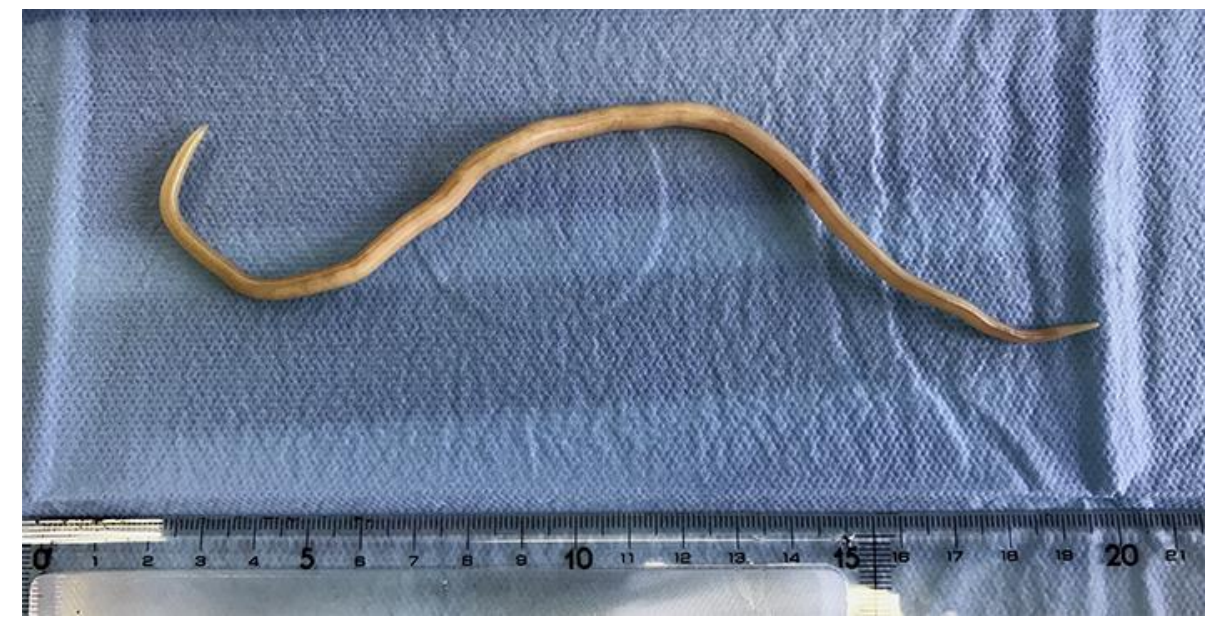

Fig. 1. The worm was discharged and identified to be a female Ascaris lumbricoides. 